\title{
Assessment of antibiotic prophylaxis in surgical patients at the Gaffrée e Guinle University Hospital.
}

\section{Avaliação da antibioticoprofilaxia em pacientes cirúrgicos no Hospital Universitário Gaffrée e Guinle.}

\author{
Marise Gouvêa 1 , Cristiane de Oliveira Novaes², Antonio Carlos Iglesias, tCBC-RJ³.
}

\begin{abstract}
A B S T R A C T
Objective: to evaluate the antibiotic prophylaxis in surgical patients at the Gaffrée e Guinle University Hospital - HUGG. Methods: we conducted a rospective study of a cohort of 256 patients undergoing elective operations between January and September 2014. We collected data on demographics, use or not of prophylactic antibiotic and the antibiotic prophylaxis following characteristics: type of antibiotic used, moment of administration and duration of postoperative use. The analyzed outcomes were "justified use or non-use of antibiotic prophylaxis", "correct antibiotic choice," "administration of the antibiotic at the right time" and "discontinuation of the antibiotic at the right time." Results: antibiotic prophylaxis was used in 91.8\% of cases. The use or non-use of antibiotic prophylaxis was justified in $78.9 \%$ of patients, the choice of the administered antibiotic was considered correct in 97.9\%, antibiotic administration was made at the right time in only $27.2 \%$ of patients and discontinuation of the antibiotic was performed at the correct time in $95.7 \%$ of cases. Conclusion: the surgical antibiotic prophylaxis was not fully adequately performed in the sample.
\end{abstract}

Keywords: Patients. Surgery. Prophylaxis. Antibiotic Prophylaxis. Guideline Adherence.

\section{INTRODUCTION}

It t is estimated that 234 million surgeries are performed worldwide annually'. Among the complications of the postoperative period, Surgical Site Infection (SSI) is responsible for a significant rate of mortality observed in the population of surgical patients. In this particular group, SSI is the most common cause of nosocomial infection and may be responsible for up to $77 \%$ of observed deaths ${ }^{2,3}$.

This complication is one of the main forms of infections related to health care in Brazil, as demonstrated in a study conducted by the Ministry of Health, which observed SSI in $11 \%$ of all surgical procedures analyzed $^{4}$. SSI occupies the third place in frequency among all the others, accounting for about $15 \%$ of all infectious processes observed in hospitalized patients ${ }^{2,5}$. Moreover, this type of complication involves financial burden to the patient, to the hospital and to the healthcare system. These facts make SSI an important public health problem and therefore a target for improving the quality of care to the patient who is candidate to surgical treatment ${ }^{6}$.

Antibiotic prophylaxis is part of a set of measures that aim to reduce SSI incidence. The main aim of antibiotic prophylaxis is to reduce the bacterial load in the wound, to assist the natural host defenses in preventing SSI ${ }^{7}$. Proper use of antibiotic prophylaxis in the perioperative period may reduce the rate of this complication in up to $50 \%{ }^{8}$.

Security practices involving patients and surgical procedures require adequate systematization of the processes implicit in this type of circumstance. The variability in the use of surgical antibiotic prophylaxis denotes a weakness in the quality of care for this population ${ }^{8}$. Efforts have been undertaken to establish protocols to guide the appropriate use of antibiotic prophylaxis for SSI prevention, whose goal is to provide health professionals with a standardized approach to the safe, effective and rational use of antimicrobials ${ }^{9}$.

The aim of this study was to evaluate the use of antibiotic prophylaxis in surgical patients at the Gaffrée e Guinle University Hospital, in the city of Rio de Janeiro.

1 - Gaffrée e Guinle University Hospital, Federal University of the State of Rio de Janeiro (UNIRIO). 2 - Public Health Institute, Federal University of the State of Rio de Janeiro (UNIRIO). 3 - Department of General and Specialized Surgery, School of Medicine and Surgery, Federal University of the State of Rio de Janeiro (UNIRIO). 
Table 1. Summary of the characteristics of the sample $(n=256)$.

\begin{tabular}{|c|c|c|}
\hline Variables & $\mathrm{N}$ & $\%$ \\
\hline \multicolumn{3}{|l|}{ Gender } \\
\hline Female & 166 & 64.8 \\
\hline Male & 90 & 35.2 \\
\hline \multicolumn{3}{|l|}{ Age group } \\
\hline $18-59$ years & 159 & 62.1 \\
\hline 60 or more years & 97 & 37.9 \\
\hline \multicolumn{3}{|l|}{$\mathrm{BMI}$} \\
\hline Underweight & 2 & 0.8 \\
\hline Eutrophic & 105 & 41.0 \\
\hline Overweight & 102 & 39.8 \\
\hline Obesity Grade I & 31 & 12.1 \\
\hline Obesity Grade II & 15 & 5.9 \\
\hline Obesity Grade III & 1 & 0.4 \\
\hline \multicolumn{3}{|l|}{ ASA } \\
\hline I & 95 & 37.1 \\
\hline$\|$ & 157 & 61.3 \\
\hline III & 4 & 1.6 \\
\hline \multicolumn{3}{|l|}{ Risk factor } \\
\hline No & 121 & 47.3 \\
\hline Yes & 135 & 52.7 \\
\hline \multicolumn{3}{|l|}{ Classification of surgery regarding contamination } \\
\hline I- clean & 96 & 37.5 \\
\hline II- potentially contaminated & 160 & 62.5 \\
\hline \multicolumn{3}{|l|}{ Use of prophylactic antibiotic } \\
\hline Não & 21 & 8.2 \\
\hline Sim & 235 & 91.8 \\
\hline
\end{tabular}

\section{METHODS}

This is a prospective study of a cohort composed of patients undergoing elective surgical procedures between January and September 2014. Of the 283 patients who were initially candidates to participate in the study, we excluded 27 because they do not meet the established criteria, the final sample thus comprising 256 cases.

We conducted the study at the Gaffrée e Guinle University Hospital (HUGG), located in the city of Rio de Janeiro, with 220 beds and about 200 monthly surgical procedures, treating only patients of the Unified Health System. The Ethics in Research Committee approved the study under the CAAE number 23959813.3.0000.5258. All patients who agreed to participate received and signed an Informed Consent Form.

For the sample composition, we considered patients from the following specialties: Gynecology, Urology, Vascular Surgery, Neurosurgery, Otolaryngology, Thoracic Surgery and General Surgery. The term general surgery includes, in this study, the specific procedures of this specialty and those specific to the Coloproctology specialties and Abdominal Surgery. At the time of the study, there was no institutional antibiotic prophylaxis protocol or some other specific recommendation, the prophylaxis being at the discretion of each surgical team. The patient inclusion criteria were individuals of both genders, aged over 18 years, classified according to physical status classification system of patients proposed by the American Society of Anesthesiologists as ASA I, II or $1 \mathrm{II}^{10}$. We excluded patients with clinical or laboratory criteria of infection at the time of surgery and patients who were already in use of antibiotic therapy.

The sample calculation considered the likelihood of appropriate use of antibiotic prophylaxis to $50 \%$, with $95 \%$ confidence interval, and type I error $<5 \%$. Thus, the estimated sample of 232 patients.

Data collection included three different times: preoperative time, perioperative one and up to the seventh postoperative day; we performed the record in a standardized form. In cases of administered antibiotic, we 
Table 2. Surgical specialties $(n=256)$.

\begin{tabular}{|c|c|c|}
\hline Variables & $\mathrm{N}$ & $\%$ \\
\hline \multicolumn{3}{|l|}{ Surgical specialties } \\
\hline General Surgery & 136 & 53.1 \\
\hline Gynecology & 48 & 18.8 \\
\hline Urology & 54 & 21.1 \\
\hline Other specialties & 18 & 7.0 \\
\hline
\end{tabular}

recorded the type of drug used, moment of administration and the duration of postoperative use.

The antibiotic prophylaxis protocol adopted in this study followed the one jointly proposed by the American Society of Health-System Pharmacists, the Infectious Diseases Society of America, the Surgical Infection Society, and the Society for Healthcare Epidemiology of America9. In addition, we also used the American College of Obstetricians and Gynecologists protocol ${ }^{11}$ for patients whose gynecologic procedures were not included in the first instrument. Based on such protocols, we recorded and analyzed the following outcomes in each case: (1) Justified use or non-use of antibiotic prophylaxis (Outcome 1): we observed the use or non-use indications of preoperative antibiotic prophylaxis for each type of procedure studied, and checked whether the chosen option was justified by the protocols. This analysis took into account the presence or absence of risk factors for surgical site infection (SSI) for the patients and surgical procedures, the classification of the surgical wound as to the potential of contamination and the type of surgical procedure. We considered the use or non-use of antibiotic prophylaxis justified: 1) if the medication was administered when properly indicated or; 2 ) when the non-use of antibiotics was properly indicated. (2) Correct antibiotic choice (Outcome 2): we evaluated if the antibiotic choice followed the aforementioned protocols. We considered the desired action spectrum, the least possible impact on the patient's microbiota, minimal adverse effects and drug allergy history. (3) Antibiotic administration at the correct moment (Outcome 3): The antibiotic administration should occurr between 30 and 60 minutes before the incision (in the case of antibiotics with short time of administration) and between 60 and 120 minutes for those requiring prolonged infusion time. We performed this analysis respecting the pharmacology of each admin- istered agent. (4) Discontinuation of antibiotic at the right time (Outcome 4): the use of antibiotic should cease in up to 24 hours after the procedure.

We analyzed the following independent variables for each patient: 1) gender; 2) age distributed in two categories (18-59 years, 60 years or older); 3) Body Mass Index (BMI) to assess the nutritional status of patients according to the World Health Organization $(\mathrm{WHO})^{12}$; 4) physical condition of the patient $\left.(\mathrm{ASA})^{10} ; 5\right)$ surgical specialty; 6) surgery classification according to the contamination potential9; 7) antibiotic prophylaxis: if administered or not 8) SSI risk factors of the patient and/or specific to the procedure performed, according to the protocol adopted in this study ${ }^{9}$, considered present with at least one of the following: a) age or over 70 years; b) diabetes mellitus; c) smoking; d) cancer; e) altered immune response (use of steroids and immunosuppressants, neutropenia, chemotherapy); f) high chance of contamination or infection of the surgical site (gastroduodenal perforation, bile and feces spill, poor nutrition, hypoalbuminemia, anemia, radiation therapy); g) increase in gastric $\mathrm{pH}$ (as gastric acidity is an effective barrier to bacterial colonization): gastric cancer, achlorhydria, use of $\mathrm{H}_{2}$ antagonists or proton pump inhibitors); h) prolonged surgical time (>120 minutes); i) obesity; j) vascular surgery on site below the pelvis; and k) presence of urinary calculi and/or urinary obstruction.

\section{STATISTICAL ANALYSIS}

We performed univariate analyzes by means of simple frequencies in order to describe the study sample, and bivariate analysis to detect differences in the distribution of independent variables for each outcome of interest, using the chi-square test. We also employed multivariate logistic regression, including the indepen- 
Table 3. Results of the outcomes studied.

\begin{tabular}{|c|c|c|}
\hline Variables & $\mathrm{N}$ & $\%$ \\
\hline \multicolumn{3}{|l|}{$\begin{array}{l}\text { Outcome 1: } \\
\text { Justified use or non-use of antibiotic prophylaxis }\end{array}$} \\
\hline No & 54 & 21.1 \\
\hline Yes & 202 & 78.9 \\
\hline \multicolumn{3}{|l|}{$\begin{array}{l}\text { Outcome 2: } \\
\text { Correct antibiotic choice }\end{array}$} \\
\hline No & 5 & 2.1 \\
\hline Yes & 230 & 97.9 \\
\hline \multicolumn{3}{|l|}{$\begin{array}{l}\text { Outcome 3: } \\
\text { Administration of the antibiotic at the correct time }\end{array}$} \\
\hline No & 171 & 72.8 \\
\hline Yes & 64 & 27.2 \\
\hline \multicolumn{3}{|l|}{$\begin{array}{l}\text { Outcome 4: } \\
\text { Discontinuation of the antibiotic at the correct time }\end{array}$} \\
\hline No & 10 & 4.3 \\
\hline Yes & 225 & 95.7 \\
\hline
\end{tabular}

Result of outcome 1 in 256 patients studied

Results of outcomes 2, 3 and in 235 patients undergoing surgical antibiotic prophylaxis

dent variables with $p \leq 0.25$ in the preliminary analysis. We expressed the results of the multivariate model as odds ratios (OR), with significance level $\alpha \leq 0.05$ and confidence interval (CI) of $95 \%$. We used the Statistical Package for Social Sciences (SPSS) for Windows, version 17.0.

\section{RESULTS}

The characteristics of the sample represented by the 256 patients studied and the analyzed outcomes are shown in Tables 1, 2 and 3.

Most patients were female (64.8\%). The age ranged from 19 to 90 years, with a mean age of $52.9 \pm 16.2$ and with a predominance of non-elderly (62.1\%).

Regarding physical status classification, the majority of the sample (61.3\%) consisted of ASA II patients. In $52.7 \%$ of the cases, we verified the presence of at least one SSI risk factor for the patients and/or for the specific procedures performed. Considering body weight, most were classified as overweight and obese (58.2\%). Regarding the degree of wound contamination, we observed that $62.5 \%$ of the sample was represented by potentially contaminated procedures.

General surgery comprised $53.1 \%$ of procedures. The most common surgical procedures were cholecystectomies (17.6\%), herniorrhaphies (14.8\%), hysterectomies (8.2\%) and thyroidectomy (7.8\%).

Antibiotic prophylaxis was used in 235 patients, or $91.8 \%$ of cases. The mean duration of antibiotic administration before surgical incision ranged from 70 minutes before the recommended time until 90 minutes after the same time, the average being $20.7 \pm 15.7$ minutes.

The use or non-use of antibiotic prophylaxis was justified in $78.9 \%$ of patients. The choice of the administered antibiotic was considered correct in $97.9 \%$. The administration of the antibiotic was carried out at the appropriate time in only $27.2 \%$ of patients. Discontinuation of the antibiotic was performed in due time in $95.7 \%$ of cases.

Table 4 shows the most relevant results of the bivariate analysis, assessing the difference in the distribution of independent variables for each outcome of interest. 
For the outcome of "justified use or non-use of antibiotic prophylaxis", the variables that showed statistically significant differences were female gender $(p=0.000)$, age $18-59$ years $(p=0.013), A S A \|(p=0.005)$, general surgery $(p=0.001)$ and the presence of some risk factor for SSI $(p=0.000)$. For the outcome "correct antibiotic choice", the presence of some risk factor for SSI $(p=0.048)$ showed a statistically significant difference.

The outcome "administration of the antibiotic at the right time" showed different results, with a statistically significant difference in the group classified as eutrophic according to BMI $(p=0.035)$ and operations classified as potentially contaminated $(p=0.024)$. Finally, the outcome "discontinuation of antibiotic at the right time" showed a distinct distribution for general surgery $(p=0.024)$.

For the multivariate logistic regression analysis, we only included the independent variables with $p \leq 0.25$ in the preliminary bivariate analysis. For the model that analyzed the outcome "justified use or non-use of antibiotic prophylaxis", the variables that showed statistically significant differences were female gender ( $O R=0.330$, 95\% Cl=0.131-0.833), the presence of some risk factor for SSI (OR=11,654; 95\% Cl=4.255-31.913) and general surgery $(\mathrm{OR}=1.798,95 \% \mathrm{Cl}=1.160-2.789)$. The model analizing the outcome "administration of the antibiotic at the right time" showed a statistically significant relationship with the procedures classified as potentially contaminated (OR=2.073, 95\% Cl=1.048-4.102).

\section{DISCUSSION}

In order to guide and advance the safety of the surgical procedures, the World Health Organization (WHO) has established, through an international agreement, a Protocol for Safe Surgery ${ }^{8}$. The study by Haynes et al. ${ }^{13}$, held by a group of institutions in different countries and using a program based on the WHO surgical Safety Checklist, which includes surgical antibiotic prophylaxis, showed a significant decrease in the operations complication and death rates. These data suggest that efforts to safe operations lead to service efficiency and can improve the safety of surgical patients.
This study evaluated the use of surgical antibiotic prophylaxis in a cohort of 256 patients at the HUGG. Any discrepancies between the present results, when compared with other previously published articles, can be partly attributed to the different research methods used, the various criteria for evaluation of adherence to antibiotic prophylaxis protocols or the type of population studied. We note that it is not part of the scope of this study to analyze the reasons for non-adherence to the antibiotic prophylaxis protocol in surgical patients. This research is characterized by exploring a theme whose studies are scarce in the medical literature.

In the present research, antibiotic prophylaxis was used in $91.8 \%$ of cases, which was similarly observed by other authors, who found rates ranging from $81.4 \%$ to $97.5 \%{ }^{14-16}$. However, other articles showed results inferior to the aforementioned frequencies, with a variation for the use of the antibiotic prophylaxis in the range of $58 \%$ to $73 \%{ }^{17-19}$.

The most frequent outcome in our observation was "correct antibiotic choice", with $97.9 \%$ of the cases studied, which we considered acceptable, since it covered almost all cases. Our findings are in agreement with the search of Castella et $a{ }^{18}{ }^{18}$, in which the choice of the antimicrobial agent was correct in $95 \%$ of surgical procedures. Malavaud et al. presented results of $91.9 \%{ }^{20}$ and $82.8 \%{ }^{17}$ in relation to this outcome, while the value found by Pittalis et $a . .{ }^{15}$ was $84.5 \%$. In Gul et al. research ${ }^{19}$, the results were $87 \%$ and $84.3 \%$ for herniorrhaphy and colorectal procedures, respectively. Nevertheless, other studies have found much lower values for the outcome "correct antibiotic choice" as reported by Mahdaviazad et al. ${ }^{21}$ (25.4\%) and Napolitano et al. ${ }^{14}$ (25.5\%). Prophylactic antibiotics should be selected according to the SSI probable causing agents, which are usually those who are part of the endogenous microbiota of the site to be operated ${ }^{22}$. Ideally, the chosen antibiotic should be of low cost, low toxicity and a have a sufficiently long half-life to maintain proper concentration until the wound closure, also taking into account the patients' safety and allergy profiles ${ }^{9}$.

We observed the "discontinuation of antibiotic at the right time" in $95.7 \%$ of the examined cases. How- 
Table 4. Bivariate analysis among the established outcomes and studied variables.

\begin{tabular}{|c|c|c|c|c|c|c|c|c|}
\hline \multirow[t]{3}{*}{ Sample variables } & \multicolumn{4}{|c|}{$\begin{array}{c}\text { Outcome 1: } \\
\text { Justified use or non-use }\end{array}$} & \multicolumn{4}{|c|}{$\begin{array}{l}\text { Outcome } 3 \text { : } \\
\text { Administration at the right time }\end{array}$} \\
\hline & \multicolumn{2}{|c|}{ No } & \multicolumn{2}{|c|}{ Yes } & \multicolumn{2}{|c|}{ No } & \multicolumn{2}{|c|}{ Yes } \\
\hline & $\mathrm{N}$ & $\%$ & $\mathrm{~N}$ & $\%$ & N & $\%$ & $\mathrm{~N}$ & $\%$ \\
\hline \multicolumn{9}{|l|}{ Gender } \\
\hline Male & 7 & 13.0 & 83 & 41.1 & 57 & 33.3 & 28 & 43.8 \\
\hline \multirow[t]{2}{*}{ Female } & 47 & 87.0 & 119 & 58.9 & 114 & 66.7 & 36 & 56.2 \\
\hline & \multicolumn{4}{|c|}{$X^{2}=14.786 ; p=0.000$} & \multicolumn{4}{|c|}{$X^{2}=2.189 ; p=0.093$} \\
\hline \multicolumn{9}{|l|}{ Age group } \\
\hline $18-59$ years & 41 & 75.9 & 118 & 58.4 & 111 & 64.9 & 34 & 53.1 \\
\hline \multirow[t]{2}{*}{60 or more years } & 13 & 24.1 & 84 & 41.6 & 60 & 35.1 & 30 & 46.9 \\
\hline & \multicolumn{4}{|c|}{$X^{2}=5.551 ; p=0.013$} & \multicolumn{4}{|c|}{$X^{2}=2.738 ; p=0.067$} \\
\hline \multicolumn{9}{|l|}{$\mathrm{BMI}$} \\
\hline Underweight & 0 & 0.0 & 2 & 1.0 & 0 & 0.0 & 2 & 3.1 \\
\hline Eutrophic & 22 & 40.7 & 83 & 41.1 & 68 & 39.8 & 28 & 43.8 \\
\hline Overweight & 19 & 35.2 & 83 & 41.1 & 71 & 41.5 & 24 & 37.5 \\
\hline Obesity Grade I & 9 & 16.7 & 22 & 10.9 & 18 & 10.5 & 10 & 15.6 \\
\hline Obesity Grade II & 4 & 7.4 & 11 & 5.4 & 13 & 7.6 & 0 & 0.0 \\
\hline \multirow[t]{2}{*}{ Obesity Grade III } & 0 & 0.0 & 1 & 0.5 & 1 & 0.6 & 0 & 0.0 \\
\hline & \multicolumn{4}{|c|}{$X^{2}=2.630 ; p=0.757$} & \multicolumn{4}{|c|}{$X^{2}=11.967 ; p=0.035$} \\
\hline \multicolumn{9}{|l|}{ ASA } \\
\hline (I) & 30 & 55.6 & 65 & 32.2 & 60 & 35.1 & 24 & 37.5 \\
\hline$\|$ & 24 & 44.4 & 133 & 65.8 & 108 & 63.2 & 39 & 60.9 \\
\hline \multirow[t]{2}{*}{ III } & 0 & 0.0 & 4 & 2.0 & 3 & 1.8 & 1 & 1.6 \\
\hline & \multicolumn{4}{|c|}{$X^{2}=10.525 ; p=0.005$} & \multicolumn{4}{|c|}{$X^{2}=0.123 ; p=0.941$} \\
\hline \multicolumn{9}{|l|}{ Surgical specialties } \\
\hline General Surgery & 37 & 58.5 & 99 & 49.0 & 90 & 52.6 & 32 & 50.0 \\
\hline Gynecology & 14 & 25.9 & 34 & 16.8 & 37 & 21.6 & 8 & 12.5 \\
\hline Urology & 2 & 3.7 & 52 & 25.7 & 32 & 18.7 & 20 & 31.3 \\
\hline \multirow[t]{4}{*}{ Other specialties } & 1 & 1.9 & 17 & 8.4 & 12 & 7.0 & 4 & 6.3 \\
\hline & \multicolumn{4}{|c|}{$X^{2}=17.354 ; p=0.001$} & \multicolumn{4}{|c|}{$X^{2}=5.441 ; p=0.142$} \\
\hline & \multicolumn{2}{|c|}{ No } & & es & \multicolumn{2}{|c|}{ No } & & es \\
\hline & $\mathrm{N}$ & $\%$ & $\mathrm{~N}$ & $\%$ & $\mathrm{~N}$ & $\%$ & $\mathrm{~N}$ & $\%$ \\
\hline
\end{tabular}

Risk factor

\begin{tabular}{lcccccccc} 
No & 48 & $88.9 \%$ & 73 & $36.1 \%$ & 81 & $47.4 \%$ & 25 & $39.1 \%$ \\
Yes & 6 & $11.1 \%$ & 129 & $63.9 \%$ & 90 & $52.6 \%$ & 39 & $60.9 \%$ \\
& \multicolumn{1}{l}{$X^{2}=47.568 ; p=0.000$} & & $X^{2}=1.298 ; p=0.161$ \\
\hline
\end{tabular}

Classification of surgeries regarding the potential of contamination

\begin{tabular}{lcccccccc} 
I-clean & 18 & 33.3 & 78 & 38.6 & 68 & 39.8 & 16 & 25.0 \\
II-potentially contaminated & 36 & 66.7 & 124 & 61.4 & 103 & 60.2 & 48 & 75.0 \\
& \multicolumn{3}{c}{$X^{2}=0.507 ; p=0.292$} & & $X^{2}=4.421 ; p=0.024$ \\
\hline
\end{tabular}

The outcomes 2 and 4 are described in the text 
ever, there is great variation in the reports relative to this outcome. The rate we found is higher than the reported by Malavaud et al. ${ }^{17}$ (91.4\%), Meeks et al. ${ }^{23}$ (82\%) and Castella et al. ${ }^{18}(80 \%)$. Differently, Askarian et al. ${ }^{24}$, Gul et al. ${ }^{19}$, Mahdaviazad et al. ${ }^{21}$, Tourmousoglou et al. ${ }^{16}$, Pitallis et al. ${ }^{15}$ and Hohmann et al. ${ }^{25}$ showed contrasting results with the present study, the values being $5.8 \%, 20 \%$, $29.4 \% 36.3 \%$ 48\% and $67.1 \%$, respectively. Prolonged administration of prophylactic antibiotics showed no benefit in preventing SSI and their unnecessary use could favor the development of antimicrobial resistance, lead to occurrence of side effects and be associated to increased direct costs of health care assistance ${ }^{26}$. For most of the operations, the administration of a single dose of the antimicrobial in prophylactic treatment is sufficient and the prophylaxis should not continue postoperatively for longer than 24 hours $^{22}$. Santana et al. study ${ }^{26}$, in which the average time of use of antimicrobials after operations was $6.6 \pm 5.6$ days, exemplify the impact of excessive use of antimicrobials for SSI prophylaxis with questionable indications, which ends up creating situations that compromise the safety of patients and increased hospital costs. We must note the current trend of antibiotic prophylaxis restricted to surgical time ${ }^{9}$.

There was justification in $78.9 \%$ of cases in this study for the "use or non-use of antibiotic prophylaxis", which reveals that the appropriate indication of antibiotic prophylaxis was not observed satisfactorily. However, this result is close to those found by other authors, whose rates varied between $81 \%$ and $88.1 \%{ }^{16,17,20,27}$. The results from Pittalis et al. ${ }^{15}$ were material, with justification in $95 \%$ of cases, while Durando et al. ${ }^{28}$ found $70.3 \%$. Nonetheless, Mahdaviazad et al. ${ }^{21}$ and Askarian et al. ${ }^{24}$ showed results inferior to those already mentioned, represented respectively by $35.4 \%$ and $2 \%$ of the cases. In a study conducted in Brazil, Souza et al. ${ }^{29}$ found no rational basis or defined criteria for almost half of prophylactically used antimicrobials. Antibiotic prophylaxis is not necessary in many surgical situations; hence, the justified use must comply with well-defined principles ${ }^{22}$.

The "administration of the antibiotic at the right time" presented with the worst result amongst all outcomes analyzed in our study, with a rate of only $27.2 \%$.
Several authors also found low frequency results, ranging from $39.7 \%$ to $53.4 \%{ }^{14,15,17,30}$. Intermediate values have been reported for this outcome, between $61.1 \%$ and $84 \%{ }^{18,20,21,23,28}$. However, Gul et al. ${ }^{19}$ and Tourmousoglouv et al. ${ }^{16}$ observed rates of $98 \%$ and $100 \%$, respectively, representing appropriate values. The timing of administration of prophylactic antibiotics should obey the time it takes to reach the blood and tissue concentrations that exceed the minimum inhibitory concentration for the microorganisms likely to colonize the surgical site ${ }^{31,32}$. Additionally, for the antimicrobial prophylaxis to be successful, it is necessary that the drug supply in the region to be operated occurs before its possible contamination ${ }^{9}$, which should be less than 60 minutes before the incision, as proposed by $\mathrm{WHO}^{13}$.

The multivariate logistic regression analysis revealed, in a statistically significant manner, the association of some factors with the outcomes of interest.

Regarding the outcome of "justified use or non-use use of antibiotic prophylaxis", female gender was an inversely related factor, while there was an association with groups of patients undergoing procedures here classified as General Surgery and with the presence of at least one risk factor for SSI. For the first two variables, this association may have occurred because of the sample characteristics, since most of the patients were female and patients admitted in General Surgery wards. As regards to the presence of at least one SSI risk factor, it is reasonable to assume that the doctor has observed more closely the indication of antibiotic prophylaxis in patients with comorbidities and that presented with conditions more favorable to SSI. Similarly, Napolitano et al. ${ }^{14}$ reported that the presence of risk factors such as, for example, advanced age and hypoalbuminemia, besides hospitalization in General Surgery wards, were associated with appropriate indication of antibiotic prophylaxis.

None of the variables showed statistical significance related to "correct antibiotic choice". We can understand that the choice of antibiotic to be used does not depend on the individual characteristics, factors present or patient's clinical condition. In reality, the correct choice of prophylactic antibiotics relates to the type of surgical procedure and the microbiota in the site to be operated, 
so that the microorganisms that colonize specific sites exhibit sensitivity profiles to certain antibiotics, which facilitates their selection ${ }^{22,32}$.

The "administration of the antibiotic at the right time" was statistically significant for the variable potentially contaminated surgery. We can assumed that this type of procedure arouses more attention of health professionals towards the risk of SSI. Differently, the studies from Simon et al. ${ }^{33}$ and Thouverez et al..$^{34}$ found that the surgical wound classified as potentially contaminated is a factor associated with a higher rate of non-compliance to the protocol adopted.

No variable was associated in a statistically significant manner with the "discontinuation of antibiotic at the right time." The result of multivariate analysis suggests that the outcome could not be associated with any independent variable, since there was no significant variability in this outcome frequency, that is, discontinuation of the antibiotic was performed in due time in most patients $\left(95.7 \%\right.$ cases). However, Wright et al. ${ }^{27}$ noted that groups of patients who more often received antibiotics for a long time were those with more comorbidities or elderly females.

Surgical antibiotic prophylaxis may be considered appropriate when it reaches values of the criteria established in the adopted protocols close to $100 \%$. From 11 analyzed articles that addressed appropriate surgical antibiotic prophylaxis, this parameter was considered inadequate in $100 \%$ of them ${ }^{14-17,20,21,23-25,28,30}$. In their systematic review of adherence to surgical antibiotic prophylaxis protocols, Gouvêa et al. ${ }^{35}$ concluded that all the studies reviewed indicated the need for greater adherence to such protocols. In our study, despite the outcomes "correct antibiotics choice" and "discontinuation of antibiotic at the right time" having reached rates close to $100 \%$, the other two outcomes did not show sufficient results. Therefore, we conclude that surgical antibiotic prophylaxis was not fully adequately performed in the sample.

This study provided an overview of the use of antibiotic prophylaxis in surgical patients in our hospital, which makes possible the improvement of this practice in the institution. However, antibiotic prophylaxis is only one of many strategies to control SSI, such as technique and surgical team experience, hospital environment, sterile surgical instruments, preoperative preparation (antisepsis, asepsis, trichotomy) and perioperative management (glycemic and temperature control) ${ }^{9}$.

\section{Acknowledgements}

We thank the participating patients, the nursing staff, the doctors of the anesthesiology services, Surgical Clinics and Specialties of thee HUGG, especially to doctors Ana Helena Aragon, Emanuela Vicente, Patricia Costa, Rafael Nascimento, Thaís Galvão, Vítor Saraiva, Marcus Lima Raquel Guimarães, Michelle Pinto, Marcellus Moreira, Diego Torres and Raquel Marques.

\title{
R E S U M O
}

\begin{abstract}
Objetivo: avaliar a antibioticoprofilaxia em pacientes cirúrgicos do Hospital Universitário Gaffrée e Guinle. Métodos: estudo prospectivo de uma coorte de 256 pacientes submetidos à operações eletivas, entre janeiro e setembro de 2014. Foram coletados dados demográficos dos pacientes, se ocorreu utilização ou não do antibiótico profilático e as seguintes características da antibioticoprofilaxia: tipo de antibiótico utilizado, momento da administração e tempo de duração do uso no pós-operatório. Os desfechos de interesse analisados foram "uso ou não uso justificado da antibioticoprofilaxia", "escolha correta do antibiótico", "administração do antibiótico no tempo correto" e "descontinuação do antibiótico no tempo correto". Resultados: a antibioticoprofilaxia foi utilizada em 91,8\% dos casos. O uso ou não uso da antibioticoprofilaxia foi justificado em 78,9\% dos pacientes, a escolha do antibiótico administrado foi considerada correta em $97,9 \%$, a administração do antibiótico foi feita no momento correto em apenas $27,2 \%$ dos pacientes e a descontinuação do antibiótico foi realizada no tempo correto em $95,7 \%$ dos casos. Conclusão: a antibioticoprofilaxia cirúrgica não foi realizada de forma plenamente adequada na amostra estudada.
\end{abstract}

Descritores: Pacientes. Cirurgia. Profilaxia. Antibioticoprofilaxia. Fidelidade a Diretrizes.

\section{REFERENCES}

1. Weiser TG, Regenbogen SE, Thompson KD, Haynes $A B$, Lipsitz SR, Berry WR, et al. An estimation of the global volume of surgery: a modelling strategy based on available data. Lancet. 2008;372(9633):139-44.

2. Mendes FF, Carneiro AF. Infecção no paciente cirúrgico: como podemos contribuir para a prevenção? In: 
Salman FC, Diego LAS, Silva JH, Moraes JMS, Carneiro AF. Qualidade e segurança em anestesiologia. Rio de Janeiro: SBA; 2012. p.143-62.

3. Mangram AJ, Horan TC, Pearson ML, Silver LC, Jarvis WR. Guideline for prevention of surgical site infection, 1999. Infect Control Hosp Epidemiol. 1999;20(4):247-80.

4. Brasil. Ministério Saúde. Agência Nacional de Vigilância Sanitária. Critérios Nacionais de Infecções Relacionadas à Assistência à Saúde. Brasil: Anvisa, 2013. Acesso em: 10 nov 2013. Disponível em: http://portal. saude.gov.br/portal/arquivos/pdf/cartilha2.pdf.

5. Emori TG, Gaynes RP. An overview of nosocomial infections, including the role of the microbiology laboratory. Clin Microbiol Rev.1993;6(4):428-42.

6. Murray BW, Huerta S, Dineen S, Anthony T. Surgical site infection in colorectal surgery: a review of the nonpharmacologic tools of prevention. J Am Coll Surg. 2010; 211(6):812-22.

7. Hall C, Allen J, Barlow G. Antibiotic prophylaxis. Surgery(Oxford). 2012;30(12):651-8.

8. WHO Guidelines for safe surgery: safe surgery saves lives [Internet]. Switzerland: World Healthy Organization; 2009 [cited 2014 Oct 14]. Available from: http://whqlibdoc.who.int/publications/2009/9789241598552_ eng.pdf.

9. Bratzler DW, Dellinger EP, Olsen KM, Perl TM, Auwaerter PG, Bolon MK, et al. Clinical practice guidelines for antimicrobial prophylaxis in surgery. Am J Health Syst Pharm. 2013;70(3):195-283.

10. American Society of Anesthesiologists [Internet]. Washington: ASA; c1995-2015 [update 2014 Oct 15; cited 2015 Feb 25]. ASA Physical Status Classification System. Disponível em: https://www.asahq. org/resources/clinical-information/asa-physical-status-classification-system.

11. ACGO practice bulletin $n^{\circ} 104$ : antibiotic prophylaxis for gynecologic procedure. ACOG Committee on Practice Bulletins--Gynecology. Obstet Gynecol. 2009;113(5):1180-9.

12. Brasil. Ministério da Saúde. Estratégias para o Cuidado da pessoa com doença crônica: obesidade. Brasília, 2014. (cadernos de Atenção Básica, n 38).
Acesso em: 15 mar 2015. Disponível em: http:// bvsms.saude.gov.br/bvs/publicacoes/estrategias_ cuidado_doenca_cronica_obesidade_cab38.pdf.

13. Haynes $A B$, Weiser TG, Berry WR, Lipsitz SR, Breizat $A H$, Dellinger $E P$, et al. A surgical safety checklist to reduce morbidity and mortality in a global population. N Engl J Med. 2009; 360(5):491-9.

14. Napolitano F, Izzo MT, Di Giuseppe G, Angelillo IF; Collaborative Working Group. Evaluation of the appropriate perioperative antibiotic prophylaxis in Italy. PLoS ONE. 2013;8(11): e79532.

15. Pittalis S, Ferraro F, Piselli P, Ruscitti LE, Grilli E, Lanini $S$, et al. Appropriateness of surgical antimicrobial prophylaxis in the Latium region of Italy, 2008: a multicenter study. Surg Infect (Larchmt). 2013;14(4):381-4.

16. Tourmousoglou CE, Yiannakopoulou E, Kalapothaki V, Bramis J, St Papadopoulos J. Adherence to guidelines for antibiotic prophylaxis in general surgery: a critical appraisal. J Antimicrob Chemother. 2008;61(1):214-8.

17. Malavaud S, Bonnet E, Vigouroux D, Mounet J, Suc B. [Prophylactic antibiotic use in gastro-intestinal surgery: an audit of current practice]. J Chir (Paris). 2008: 145(6):579-84. French.

18. Castella A, Charrier L, Di Legami V, Pastorinho F, Farina EC Argentero PA, et al. Surgical site infection surveillance: analysis of adherence to recommendations for routine infection control practices. Infect Control Hospl Epidemiol. 2006;27(8):835-40.

19. Gul Y A, Hong LC, Prasannan S. Appropriate antibiotic administration in elective surgical procedures: still missing the message. Asian J Surg. 2005;28(2):104-8.

20. Malavaud S, Bonnet E, Atallah F, El Farsaoui R, Roze J, Mazerolles $\mathrm{M}$, et al. [Evaluation of clinical practice: audit of prophylactic antibiotics in urology]. Prog Urol. 2008;18(6):395-401. French.

21. Mahdaviazad $H$, Masoompour SM, Askarian M. Iranian surgeons' compliance with the American Society of Health-System Pharmacists guidelines: antibiotic prophylaxis in private versus teaching hospitals in Shiraz, Iran. J Infect Public Health. 2011;4(56):253-9. 
22. Tavares W. Antibióticos e quimioterápicos para o clínico. 3a ed. São Paulo: Atheneu; 2014.

23. Meeks DW, Lally KP, Carrick MM, Lew DF, Thomas EJ, Doyle PD, et al. Compliance with guidelines to prevent surgical site infections: as simple as 1-2-3?: Am J Surg. 2011;201(1):76-83.

24. Askarian $M$, Moravveji AR, Mirkhani $H$, Namazi $\mathrm{S}$, Weed $\mathrm{H}$. Adherence to American Society of Health-System Pharmacists surgical antibiotic prophylaxis guidelines in Iran. Infect Control Hosp Epidemiol. 2006;27(8):876-8.

25. Hohmann C, Eickhoff C, Radziwill R, Schulz M. Adherence to guidelines for antibiotic prophylaxis in surgery patients in German hospitals: a multicentre evaluation involving pharmacy interns. Infection. 2012;40(2):131-7.

26. Santana R, Viana AC, Santiago JS, Menezes MS, Lobo IM, Marcellini PS. The cost of excessive postoperative use of antimicrobials: the context of a public hospital. Rev Col Bras Cir. 2014;41(3):149-54.

27. Wright JD, Hassan K, Ananth CV, Herzog TJ, Lewin SN, Burke WM, et al. Use of guideline-based antibiotic prophylaxis in women undergoing gynecologic surgery. Obstet Gynecol. 2013;122(6):1145-53.

28. Durando P, Bassetti M, Orengo G, Crimi P, Battistini $A$, Bellina $D$, et al. Adherence to international and national recommendations for the prevention of surgical site infections in Italy: results from an observational prospective study in elective surgery. Am J Infect Control. 2012;40(10):969-72.

29. Souza HP, Vilhordo DW, Breigeiron R, Alessandretti MB, Silva TGB. Auditoria no uso de antimicrobianos em enfermaria cirúrgica. Rev Col Bras Cir. 2008;35(4):216-20.
30. Machado-Alba JE, Morales-Plaza CD, Solarte MJ. Adherencia a antibioterapia prequirúrgica en intervenciones torácicas y abdominales en el Hospital Universitario San Jorge, de Pereira. Rev Cienc Salud. 2013;11(2):205-16.

31. Bratzler DW, Houck PM; Surgical Infection Prevention Guideline Writers Workgroup. Antimicrobial prophylaxis for surgery: an advisory statement from the National Surgical Infection Prevention Project. Am J Surg. 2005;189(4):395-404.

32. James $M$, Martinez EA. Antibiotics and perioperative infections. Best Pract Res Clin Anaesthesiol. 2008;22(3):571-84.

33. Simon AM, Dzierzek AC, Djossou F, Couppie P, Blaise $N$, Marie $M$, et al. [Factors associated with non-compliance to surgical antimicrobial prophylaxis guidelines during a prospective audit]. Ann Fr Anesth Reanim. 2012;31(2):126-31. French.

34. Thouverez M, Lallemand S, Bailly P, Betrand X, Talon D. [Determination of indicators for non-compliance with guidelines for surgical antimicrobial prophylaxis]. Pathol Biol (Paris). 2002;50(9):547-51. French.

35. Gouvêa M, Novaes CO, Pereira DM, Iglesias AC. Adherence to guidelines for surgical antibiotic prophylaxis: a review. Braz J Infect Dis. 2015;19(5):517-24.

Received in: 26/02/2016

Accepted for publication: 04/06/2016

Conflict of interest: none.

Source of funding: none.

\section{Mailing address:}

Marise Gouvêa

E-mail: marisegouveia.mg@gmail.com 